\title{
Fracture flow characterization with low-noise SP logging
}

André C. G. Kowalski ${ }^{1}$, Carlos A. Mendonça ${ }^{1}$, Ulrich S. Ofterdinger ${ }^{2}$

${ }^{1}$ Departamento de Geofísica, IAG-USP

${ }^{2}$ Queen's University Belfast

Copyright 2019, SBGf - Sociedade Brasileira de Geofísica

This paper was prepared for presentation during the $16^{\text {th }}$ International Congress of the Brazilian Geophysical Society held in Rio de Janeiro, Brazil, 19-22 August 2019.

Contents of this paper were reviewed by the Technical Committee of the $16^{\text {th }}$ International Congress of the Brazilian Geophysical Society and do not necessarily represent any position of the SBGf, its officers or members. Electronic reproduction or storage of any part of this paper for commercial purposes without the written consent of the Brazilian Geophysical Society is prohibited.

\section{Abstract}

Geophysical well logging has been applied for fracture characterization in crystalline terrains by physical properties measurements and borehole wall imaging. Some of these methods can be applied to monitor pumping tests to identify fractures contributing with groundwater flow and, with this, determine hydraulic conductivity and transmissivity along the well. We present a procedure to identify fractures contributing to the groundwater flow by using spontaneous potential (SP) measurements generated by electrokinetic processes when the borehole water head is lowered and then monitored while recovering. The electrokinetic model for flow through a tabular gap is used to interpret the measured data and determine the water head difference that drives the flow through the fracture. We present preliminary results at a test site in crystalline rocks, in the campus of the University of São Paulo.

\section{Introduction}

Crystalline rocks commonly exhibit low primary porosity leading to groundwater flow to be conditioned by fracture density, aperture and connectivity (Busse et al., 2016). Characterizing the hydraulic properties of fractures is crucial for modelling groundwater flow in crystalline terrains with most of the existing techniques relying on active pumping or injection testing or in some cases on well logging (NRC, 1996). Paillet et al. (2012) monitored flow change in a well as a result of pumping an adjacent well to determine fracture transmissivity and storage parameters, subsequently validated with tracer tests.

Fracture characterization is also important for identifying open water-bearing fractures in tunnel construction to ensure safety standards for working. Stumm et al. (2013) employed 36 wells at a construction pit to map intervals with higher fracturing degree by using optical logging images with statistical characterization of fracture directions and apertures. Keller et al. (2014) applied the FLUTe technique, in which a flexible liner is lowered into the borehole forcing the water flow formation inward, to estimate fracture transmissivities by using Thiem's equation. FLUTe technology and pumping tests with packers to isolate intervals are highly invasive (and expensive) compared to indirect geophysical logging techniques. However, geophysical logging is of limited use for quantifying hydraulic parameters, including quantifying the driving hydraulic pressure field acting on the water-bearing fracture system.

In principle, the SP (spontaneous potential) logging can sense the water flow through porous or fissured media by isolating potentials generated by electrokinetic phenomena. Just after drilling, the SP signal is mostly originated by electrochemical gradients (concentration gradient between the formation and borehole waters) with amplitudes up to $100 \mathrm{mV}$ (Telford et al., 1990). This potential vanishes as the borehole waters are homogenized by diffusion and advection. For mature wells, the SP signals are mainly from electrokinetic origin, nevertheless achieving much lower amplitudes up to 10 $\mathrm{mV}$ (Revil et al., 2006; Mendonça et al., 2012; Lee and $\mathrm{Kim}, 2015)$. The electrokinetic potential is caused by the electrical double layer (EDL, Fig.1) (Revil et al., 2012; Kirkby et al., 2016) developed at the mineral-liquid interface, in which part of the dissolved ions are immobilized and a diffuse layer can move as the groundwater flows. Therefore there is a direct relationship between electrokinetic signals and the velocity of the groundwater flow through fractured or granular porous media. Electrokinetic potentials are observed either in natural flow conditions or when induced by pumping tests.

The amplitude of the SP signal from electrokinetic contribution tends to be very low, usually at the background noise-level of data measured with multifunctional probes simultaneously measuring SP and resistivity data. Major potentials from current sources (2 or 3 orders of magnitude higher) for resistivity measurements may generate noisy-fields well above those expected from electrokinetic effects. To accurately measure smaller SP signals, passive probes with no current sources and careful treatment of electrodes are required.

We present a conceptual model for interpreting SP data of electrokinetic origin when the water head of a well is lowered and its recovery is monitored with a low-noise SP probe. Signal variations in successive SP runs are interpreted by using the planar gap model of charged interfaces (Masliyah and Bhattacharjee, 2006), to recognize water heads in which the flow through a fracture nulls the electrokinetic potential. We present preliminary field data showing that observed SP variations behave as expected from this gap model, allowing the identification of fractures with higher transmissivities and inference of driving water heads. Results are discussed using other geophysical logs (optical imaging, normal resistivity) and core samples description.

\section{Electrokinetics in a planar gap}

A simple way to represent a fracture is by a gap with constant separation between two charged interfaces with same interfacial properties. A charged interface is formed 
by electric double layer (EDL) structures as illustrated in Figure 1. The water flow along the fracture plane displaces the ions of the diffuse layer of the EDL generating a conduction current opposite to the flow of water (Kirkby et al., 2016).

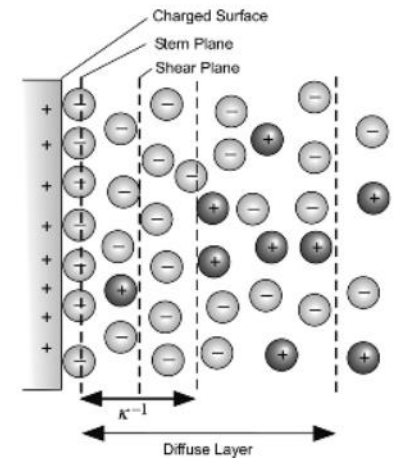

Figure 1 - Model for the electric double layer formed in fracture surface when immersed in an electrolyte (Adapted from Masliyah and Bhattacharjee, 2006).

Under a pressure gradient ( $P 1>P 2$, in Figure 2), the water flowing through the fracture produces a difference of potential with negative values where the water enters the fracture and positive values where it exits.

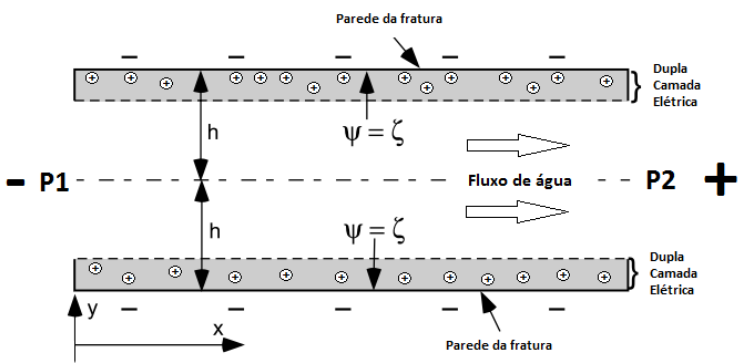

Figure 2 - Water flow in a fracture gap model. Gradient $P_{2}>P_{1}$ between the fracture ends drives the flow from left to right, $\psi$ is the surface potential (in this case the same as $\zeta$, the zeta potential) usually negative. $2 h$ is the fracture aperture (Adapted from Masliyah and Bhattacherjee, 2006).

The pressure gradient applied to the fracture is related (Masliyah and Bhattarcherjee, 2006) to the electrical potential $\Delta V(\mathrm{~V})$ as

$$
\Delta V=\frac{\varepsilon \zeta}{\eta \sigma}\left[1-\frac{\tanh (\kappa h)}{\kappa h}\right]\left(P_{2}-P_{1}\right)(1)
$$

where $\varepsilon$ is the water dielectric permittivity $\left(\mathrm{CV}^{-1} \mathrm{~m}^{-1}\right), \zeta$ is the zeta potential $(\mathrm{V}), 2 h$ is the fracture aperture $(\mathrm{m}), \eta$ is the water viscosity (Pa.s) and $\sigma$ is the water bulk conductivity $(\mathrm{S} / \mathrm{m})$. Parameter

$$
\kappa^{-1}=\left(\frac{\varepsilon k_{B} T}{2 e^{2} z^{2} n_{\infty}}\right)^{1 / 2}
$$

Is the Debye length $\left(\mathrm{m}^{-1}\right)$, a characteristic length for the EDL thickness, $k_{B}=1.38 \times 10^{-23} \mathrm{JK}^{-1}$ is the Boltzmann constant, $T$ the temperature $(\mathrm{K}), e$ the elementary charge (C), $z$ the electrolyte valence (1:1 solution assumed), and $n_{\infty}$ the ionic concentration in the bulk solution $\left(\mathrm{m}^{-3}\right)$. Equation 2 shows the electrokinetic potential is null when $P_{1}=P_{2}$. This property will be used to evaluate a field test intending to determine the water head in which this potential nulls, from variable pressure $P_{1}$, as the water head within the well is recovering after have been lowered.

\section{SP signals during recovery tests}

In mature wells, with no concentration gradient between borehole and formation waters, the contribution of electrochemical potentials is minor but still a SP variation with depth is often observable. This background potential can be disturbed by subtle changes in the water flow regime, for example by lowering the borehole water head by a few of meters ( 4 to $5 \mathrm{~m}$ in our case). The water head lowering triggers electrokinetic signals because water starts to flow into the well in order to recover its former equilibrium water head. Water inflow, however, occurs through distinct water-bearing fractures along specific zones of the well, which then can be identified by tracking variations in the SP signal as the water head recovers. A crucial point in this analysis is identifying the natural background field, from which departures due to electrokinetic effects are observed near fractures with water inflow. Deviations in the SP amplitude, $V_{i}$, can be measured for water head elevations $Z_{i}, i=1: n$ as the water head returns to its original static level, $Z_{s}$. Assuming that $p_{i}=\rho g Z_{i}$ represents the water pressure acting at the fracture depth within the borehole, the characteristic water head, $Z_{c}$, where $\Delta V=0$ (subscript "c" standing for zerocrossing) determines pressure $p_{2}$ that drives the flow at the opposite ending of the fracture as $p_{2}=\rho g Z_{c}$. This procedure can be repeated to each fracture along the well showing SP variations to determine the pressure field driving the flow through specific fractures. A fracture with $Z_{c}=Z_{w t}-Z_{f} \quad$ (difference between water table and fracture elevations) points to a fracture connected to an unconfined aquifer. The condition $Z_{c}>Z_{w t}-Z_{f}$ otherwise is indicative of a fracture under confined conditions.

Figure 3 illustrates characteristic points to be identified in tracking SP variations as the water table is recovered by natural water inflow.

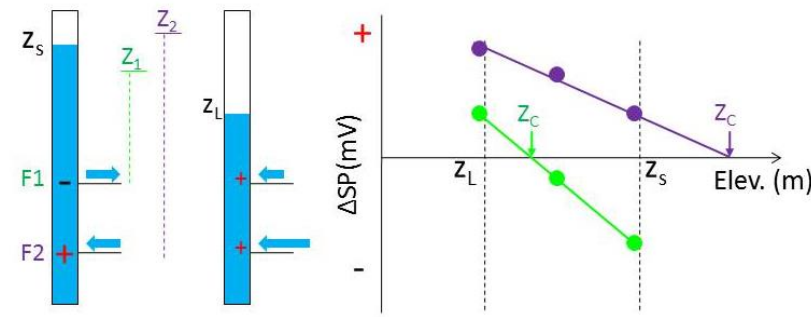

Figure 3 - Schematic of two fractures in a borehole subjected to water heads of $Z_{1}$ and $Z_{2}$. Elevation $Z_{s}$ is the static water head of the well; $Z_{L}$ is the water head after water abstraction by pumping. The electrical signal polarity indicates entrance or exiting of water through the fractures. Elevation $Z_{c}$ in which $\Delta V=0$ (zerocrossing water head) gives the water head that drives the flow through the fracture.

\section{Experimental procedures}

We developed a low noise SP probe by adapting a resistivity probe with 4 lead electrodes, formerly used for short and long normal resistivity logging. The uppermost electrode of the probe was used as reference electrode, with potential differences measured with respect 
electrodes 16 " and 32 " below the reference electrode. The electrodes were finely polished and then coated with $\mathrm{Pb}-\mathrm{Cl}$ to avoid direct exposition of the metal to the water, usually a source of spurious (redox) potentials. The probe was adapted to a Robertson Geologging winch (Mini Winch with $175 \mathrm{~m}$ range), the data acquisition carried out with an Arduino control system specially developed for the test. Difference of potentials were recorded by an ADC (analogic to digital converter) ADS1115 16-bits, and gain of $2 / 3$, given resolution of $0.1875 \mathrm{mV}$. The electrodes were left to stabilize immersed in the borehole water until stable measurements for given positions or recovering the same background field within acceptable error margin in repeated logging runs.

Since potential differences are taken along the well, a single fracture with water inflow, associated with a positive $\Delta V$ (Figure 4a), gives a "plus-minus" response, for ddp measurements between a rover electrode $M$ (below) and reference electrode $\mathrm{N}$ (above). This plusminus response is illustrated in Figure $\mathbf{4 b}$, the depth of the fracture with water inflow positioned where the SP signal crosses the zero. For a single fracture, maximum ddp values (in absolute values) are expected when one of the electrodes ( $\mathrm{M}$ or $\mathrm{N}$ ) is just in front of the fracture; the plus and minus deviations must then show the same amplitude. This characteristic plus-minus response can be regarded as indicative of electrokinetic signals associated to a single fracture, once isolated from the background SP field observed in the well. The sign of the ddp changes for fractures with borehole-to-formation flow, the polarity signal going from negative to positive ("minusplus" signature)
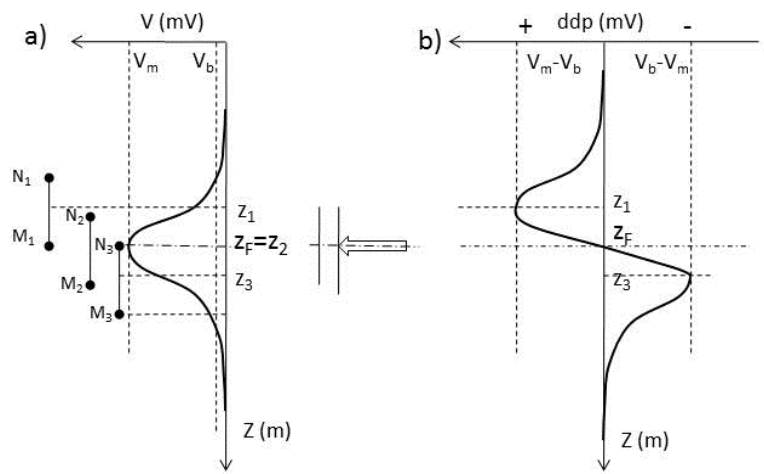

Figure 4 - Expected potential signals from water inflow to the borehole from a fracture at depth $Z_{F}$, as measured by a pair of electrodes $M-N$ with centers in depths $Z_{1}, Z_{2}$, and $Z_{3}$. Positive potential for the water inflow (left) and ddp variation along the well as measured by a pair of $M-N$ electrodes (right). $V_{\max }$ and $V_{\min }$ are limiting values for the $S P$ variation, such that $V_{\max }-V_{\min }=$ $V_{\min }-V_{\max }$

\section{Test area and results}

The proposed procedure was tested at a borehole of SCGR (Shallow Geophysics Controlled Test Site) of the IAG-USP, drilled in 2003. The well is cased until $53 \mathrm{~m}$ depth with sediments and then open down to $80 \mathrm{~m}$ with fractured gneiss (Porsani et al., 2004). A $20 \mathrm{~m}$ thick argillite layer occurs at the bottom of the sedimentary pack confining the crystalline aquifer from free-aquifer developed in poor-sorted sandstones above the argillite. Due to lateral extension of the argillite covering, the recharge of the crystalline aquifer is expected to explore wider sub-horizontal fractures connected to local hills where the crystalline basement outcrops.

OPTV imaging of the borehole wall (Figure 5) identifies the depths of 36 fractures as well as their orientations and dips. Statistical analysis identifies two main families of fractures, the most frequent one with sub-horizontal attitude (Figure 6). Despite the high number of fractures, only four of them show centimeter-scale apertures, most situated at the top of the crystalline section, at depths of $54.5,56,60$ and 65 meters.

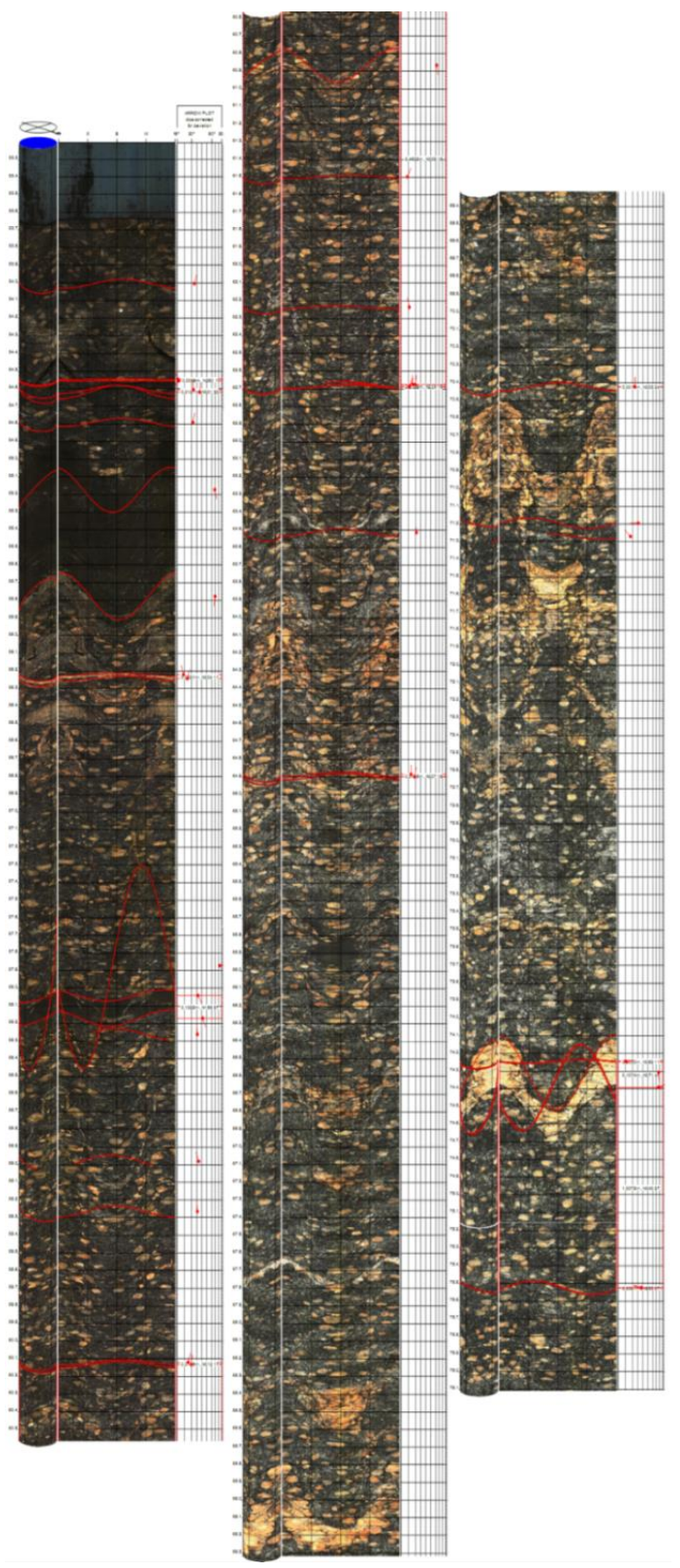

Figure 5 - Optical log for the borehole wall at the crystalline section of the SCGR testing well. Red lines indicate fracture locations and their respective orientation and dip computed from imaging processing. 
PROJEÇÃOPLANAR

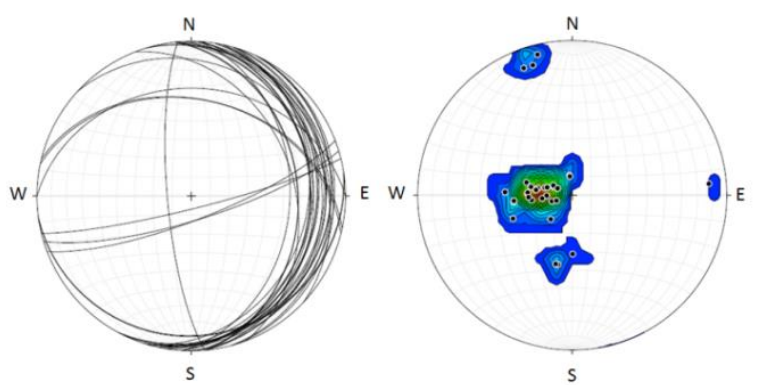

Figure 6 - Stereogram with planar and pole projections of fractures identified from the optical log.

In addition to the SP logs, electrical resistivity logging was also conducted with measurements of electrical resistance (short, N16, and long, N64, normal) and single point resistance (SPR) which are shown in figure 7 . It is possible to identify some deflections toward lower values in these logs, mainly on the resistivity curves, being some of these at the same depth of main fractures identified from the OPTV. One of these depths is around the $56 \mathrm{~m}$ where there is deflection on both resistivity curves as well as on the SPR log.

There is a close association between open fracture at 56 $\mathrm{m}$ with zero-crossing potential in the plus-mines SP variation (Figure $\mathbf{7 b}$ ). This means that out of 36 fractures identified in the well, the fracture $56 \mathrm{~m}$ deep is a major contributor to the water recomposing the well. In general the water head recovering in this well is very slow $(5 \mathrm{~m}$ recovered in 4 days) suggesting that most of the fractures are not open.

As shown in figure $\mathbf{4 b}$, the plus-minus deflection prescribed from the planar gap model for SP deviations are observed in field conditions, as long as the water head of the well returns to its original position after having been lowered by the water abstraction. Plus-minus deflections are restricted to the top of the crystalline aquifer. Superposition of individual contributions in some levels prevents the identification of single plus-minus patterns. Deflections are compatible with water inflow, since they go from positive to negative downhole (reference electrode at the probe upper position). It is worth to note that SP deviations get lower as the water level is recovering since the pressure gradients are dropping. SP runs 2, 3, and 4 were taken 30,100 and 170 minutes after the water abstraction of $80 \mathrm{~L}$, with corresponding water head variations of $0.992,1.334$ and $1.608 \mathrm{~m}$ above $Z_{L}$ elevation of $17.901 \mathrm{~m}$.
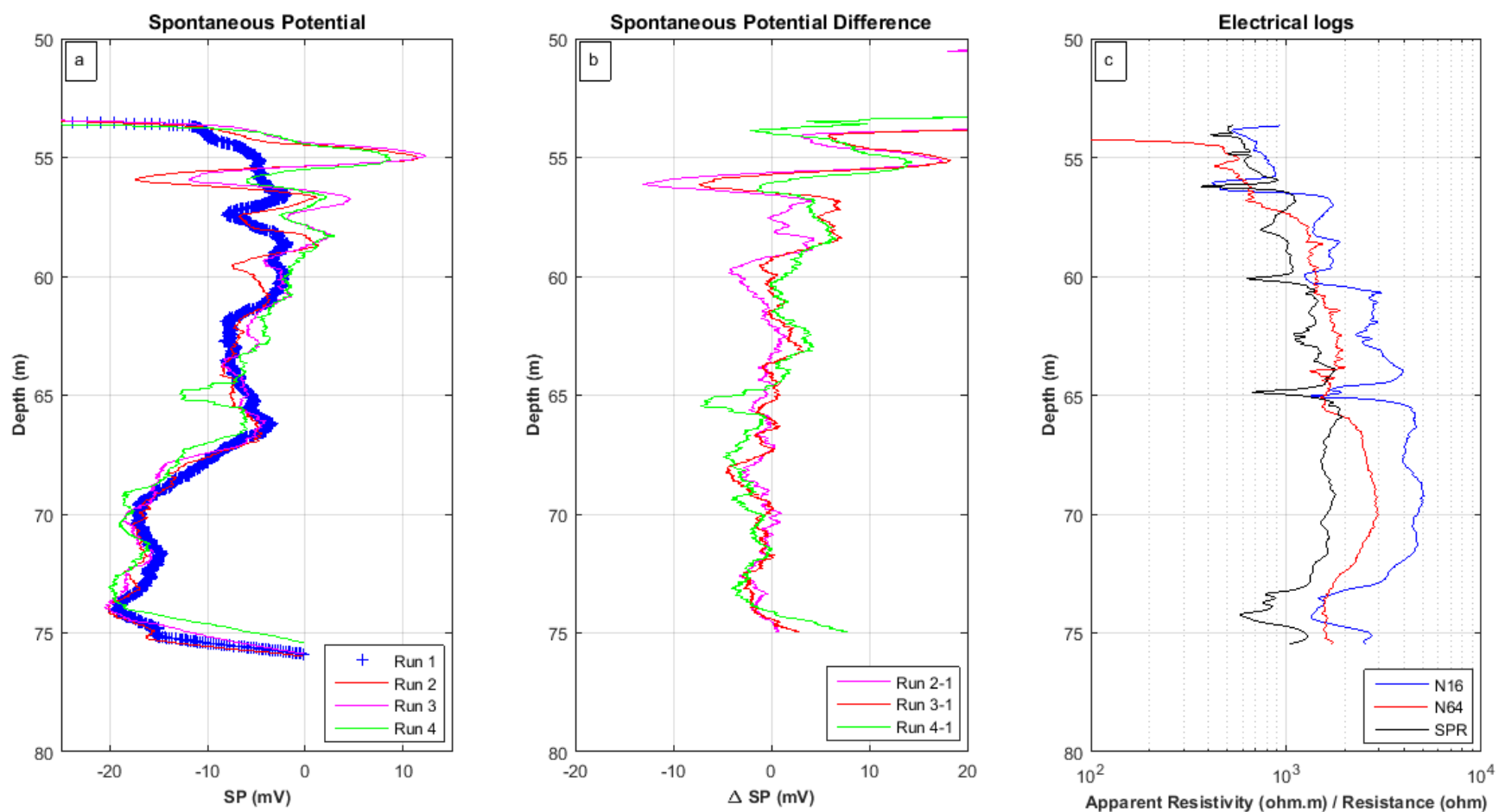

Figure 7-Electrical logs at crystalline rocks of the SCGR of IAG-USP. a) Low-noise SP signals, Run-1 as the background field and runs 2 , 3 , and 4 as the water head in the well was $16.909,16.567$ and16.293 $\mathrm{m} ; \mathrm{b}$ ) Difference of SP signals with respect the background field of the Run 1; c) Normal 16 and 64 resistivity logs and SPR (single point resistance) log. 
Although the SP deflections are evident, the variation of water head was rather small to cover a broad variation of SP amplitudes. Amplitude variations for each depth were $-13.01,-7.34$ and $-1.15 \mathrm{mV}$. These values are shown in Figure 8, which infers a zero-crossing $(\triangle S P=0)$ at elevation of $16.2 \mathrm{~m}$. Regarding that $Z_{s}$ is at $9.404 \mathrm{~m}$ the difference $Z_{c}-Z_{s} \mathrm{~m}$ implies a water head of $+6.8 \mathrm{~m}$ driving the flow through the fracture at depth $55.5 \mathrm{~m}$. The value of $+6.8 \mathrm{~m}$ is then indicative of the confining water head at this fracture.

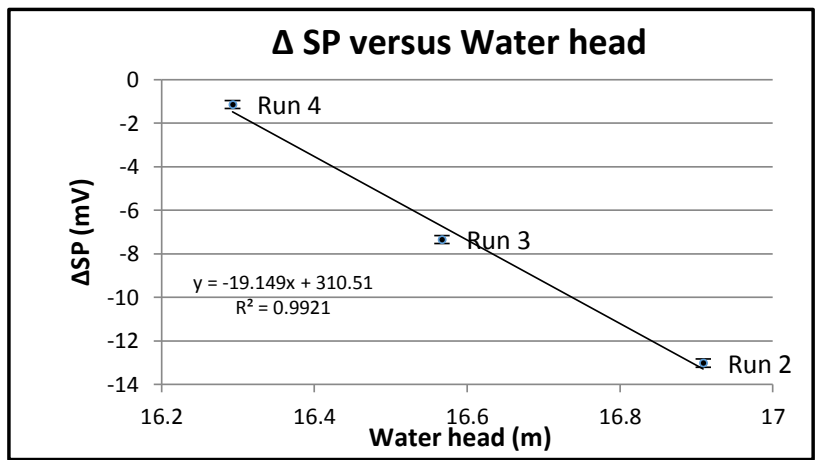

Figure 8 - Spontaneous potential amplitude variations for $3 S P$ logging runs after pumping. A linear fit was done in order to find the value at which $\triangle S P=0$.

\section{Discussion}

In general, the field test at SCGR shows promising results in applying low-noise SP probes to detect electrokinetic signals generated by induced water flow through open fractures. We observe SP variations as expected from simple gap models with electrokinetic response despite the presence of significant noise in the data, compared to the low amplitude of observed signals. Future work must cover a broader range of water levels in the borehole, possibly by additional background measurements following well recovery. Further procedures to remove noisy static shifts (as observed in run 4 at $65 \mathrm{~m}$ deep, figure 7) still are required to improve data quality.

The SP variation suggests that water entrance into the well occurs at the interface between weathered and fresh blocks at the top of the crystalline massive. This weathering degree contrast was observed in core samples and recognized by darker colors for the gneiss at the top levels. As the crystalline aquifer is confined by the $20 \mathrm{~m}$ thick layer of argillite, a wide lateral expression can be expected from fractures contributing to water well inflow, possible a major expression of a local weathering front. Another evidence of water flowing in this upper interval with SP deviations is the presence of ironhydroxides coating fissure interfaces, indicative of ongoing weathering processes.

Our results show that spontaneous potential logs can be applied to characterize and define hydraulic active fractures in crystalline rocks. The polarity of the SP signal can be used to identify the direction of the water flow, if entering or exiting the well.

\section{References}

Busse, J., Paillet, F. L., Hossack, A., Bringemeier, D., Scheuermann, A., Li, L. (2016) Field performances of the heat pulse flow meter: Experiences and recommendations, Journal of Applied Geophysics, v. 126, pp. 158-171, doi: 10.1016/j.jappgeo.2016.01.021

Keller, C. E., Cherry, J. A., Parker, B. L. (2014) New Method for Continuous Transmissivity Profiling in Fractured Rock, Groundwater, v. 52 (3), pp. 352-367, doi: 10.1111/gwat.12064.

Kirkby, A., Heinson, G., Krieger, L. (2016) Relating permeability and electrical resistivity in fractures using random resistor network models, Journal of Geophysical Research: Solid Earth, v. 121, pp. 19, doi: 10.1002/2015JB012541.

Lee, H. B., Kim, B. W. (2015) Characterisation of hydraulic-active fractures in a fractured granite aquifer, Water $S A, v .41(1)$, pp. 139-148, doi: 10.4314/wsa.v41i1.17.

Masliyah, J. H., Bhattacharjee, S. (2006) Electrokinetic and colloid transport phenomena, John Willey \& Sons, Inc., 679 pp.

Mendonça, C. A., Dotti, G. C., Maida, C., Silva, N. (2012) Tank experiments with borehole self-potential data, Geophysics, v. 77(1), doi: 10.1190/geo2011-0176.1.

National Research Council (NCR, 1996) Rock Fractures and Fluid Flow: Contemporary Understanding and Applications, Committee on Fracture Characterization and Fluid Flow, National Academy Press, 568 pp.

Paillet, F. L., Williams, J. H., Urik, J., Lukes, J., Kobr, M., Mares, S. (2012) Cross-borehole flow analysis to characterize fracture connections in the Melechov Granite, Bohemian-Moravian Highland, Czech Republic, Hydrogeology Journal, v. 20 (1), pp. 143-154, doi: 10.1007/s10040-011-0787-1.

Porsani, J.L., Borger, W. R., Elies, V. R., Diogo, L. A., Hiodo, F. Y., Marrano, A., Birelli, C. A. (2004) Investigações geofísica de superfície e de poco no sítio controlado de geofísica rasa do IAG-USP, Revista Brasileira de Geofísica, v. 22 (3), pp. 245-258, doi: $10.1017 /$ CBO9781107415324.004.

Revil A., Titov K., Doussan C., Lapenna V. (2006) Applications of the Self-Potential Method to Hydrological Problems. In: Vereecken H., Binley A., Cassiani G., Revil A., Titov K. (eds) Applied Hydrogeophysics. NATO Science Series, vol 71. Springer, Dordrecht, doi: 10.1007/978-1-4020-4912-5_9.

Revil, A., Karaoulis, M., Johnson, T., Kemna, A. (2012) A review: some low-frequency electrical methods for subsurface characterization and monitoring in hydrogeology, Hydrogeology Journal, v. 20 (4), doi: 10.1007/s10040-011-0819-x.

Stumm, F., Chu. A., Joesten, P. K., Noll, M. L., Como, M. (2013) Delineation of Fractures, Foliation, and Groundwater-flow Zones of the Bedrock at the Harlem River Tunnel in Northern New York County, New York, 20 th Conference on the Geology of Long Island and Metropolitan New York, Stony Brook University, pp. 112.

Telford, W. M., Geldart, L. P., Sheriff, R. E. (1990) Applied Geophysics, Cambridge: Cambridge University Press. 